\title{
Reservoir characterisation of aquifers for direct heat production: Methodology and screening of the potential reservoirs for the Netherlands
}

\author{
M.P.D. Pluymaekers ${ }^{1}{ }^{*}$, L. Kramers ${ }^{1}$, J.-D. van Wees ${ }^{1,2}$, A. Kronimus ${ }^{1}$, S. Nelskamp ${ }^{1}$, \\ T. Boxem ${ }^{1} \&$ D. Bonté ${ }^{1}$
}

1 TN0 - Geological Survey of the Netherlands, P.0. Box 80015, 3508 TA Utrecht, the Netherlands.

2 Utrecht University, Faculty of Geosciences, P.0. Box 80021, 3508 TA Utrecht, the Netherlands.

* Corresponding author. Email: maarten.pluymaekers@tno.nl.

Manuscript received: October 2011, accepted: August 2012

\begin{abstract}
Geothermal low enthalpy heat in non-magmatic areas can be produced by pumping hot water from aquifers at large depth (>1 km). Key parameters for aquifer performance are temperature, depth, thickness and permeability. Geothermal exploration in the Netherlands can benefit considerably from the wealth of oil and gas data; in many cases hydrocarbon reservoirs form the lateral equivalent of geothermal aquifers. In the past decades subsurface oil and gas data have been used to develop 3D models of the subsurface structure. These models have been used as a starting point for the mapping of geothermal reservoir geometries and its properties. A workflow was developed to map aquifer properties on a regional scale. Transmissivity maps and underlying uncertainty have been obtained for 20 geothermal aquifers. Of particular importance is to take into account corrections for maximum burial depth and the assessment of uncertainties. The mapping of transmissivity and temperature shows favorable aquifer conditions in the northern part of the Netherlands (Rotliegend aquifers), while in the western and southern parts of the Netherlands aquifers of the Triassic and Upper Cretaceous / Jurassic have high prospectivity. Despite the high transmissivity of the Cenozoic aquifers, the limited depth and temperature reduce the prospective geothermal area significantly.

The results show a considerable remaining uncertainty of transmissivity values, due to lack of data and heterogeneous spatial data distribution. In part these uncertainties may be significantly reduced by adding well test results and facies parameters for the map interpolation in future work. For underexplored areas this bears a significant risk, but it can also result in much higher flowrates than originally expected, representing an upside in project performance.
\end{abstract}

Keywords: Geothermal energy, regional transmissivity mapping, aquifer.

\section{Introduction}

Geothermal heat production from sedimentary basins in non magmatic settings can provide an important source of renewable energy in the future (e.g. IEA, 2011). In these settings hot water is produced from aquifers (water bearing layers) at large depth (>1 km; Ungemach et al., 2005). The energy is extracted through a heat exchanger and used for spatial heating, adsorption cooling or greenhouse heating. After cooling the water is reinjected. The well configuration consisting of an injection and production well is generally referred to as a doublet.
The produced thermal power $(\mathrm{E})$ is linearly proportional to the temperature difference of produced and reinjected temperature $\left(\Delta \mathrm{T}=\mathrm{T}_{\text {production }}-\mathrm{T}_{\text {injection }}\right)$ and flow rate of the produced water $\left(\mathrm{Q}\left(\mathrm{m}^{3} / \mathrm{h}\right)\right.$; Van Wees et al., this issue):

$$
\mathrm{E}[\mathrm{MWth}] \approx 1200 \Delta \mathrm{T} \cdot \mathrm{Q}
$$

For a particular aquifer the production temperature $\mathrm{T}_{\text {production }}$ can be predicted from the geothermal gradient and the depth of the aquifer. The temperature of the produced water at geothermal production flow rates is almost equal to the temperature of the aquifer rocks. The subsurface of the Netherlands shows 
an average geothermal gradient of approximately $31^{\circ} \mathrm{C} / \mathrm{km}$, although the temperature gradient can vary between 25 and $40^{\circ} \mathrm{C} / \mathrm{km}$ depending on geological setting (Bonté et al., this issue). Given an average surface temperature of $10^{\circ} \mathrm{C}$, this means that at $1200 \mathrm{~m}$ depth temperatures are sufficiently high for greenhouse heating ( $\mathrm{T}_{\text {production }}>45^{\circ} \mathrm{C}$ ) and at $1800 \mathrm{~m}$ depth temperatures are sufficiently high for spatial heating $\left(\mathrm{T}_{\text {production }}>65^{\circ} \mathrm{C}\right)$. In any case, aquifers shallower than 1000 $m$ depth are not favorable for heat production. The flow rate 0 depends on the hydrological properties of the aquifer and engineering design of the wells (Van Wees et al., this issue). The transmissivity (the mathematical product of aquifer thickness and permeability) significantly determines the flow rate which can be achieved as the result of a pressure difference applied to the wells. In summary, temperature, depth, thickness and porosity/permeability of aquifers are key parameters to obtain for a proper geothermal characterisation.

Earlier studies on the geothermal potential of the Netherlands (TNO-NITG, 2004; Van Doorn \& Rijkers, 2002) were based on a rather qualitative assessment, not taking into account detailed mapping and well property information. These studies identified aquifers in three major stratigraphic group including the Permian Rotliegendes, Triassic and Early Cretaceous (Fig. 2a).

In the Netherlands, prospective areas for geothermal exploration largely correspond to areas in which hydrocarbon exploration and production has taken or takes place. Therefore, geothermal exploration can take considerable advantage from the existing oil and gas data. Over the past 30 years over 5000

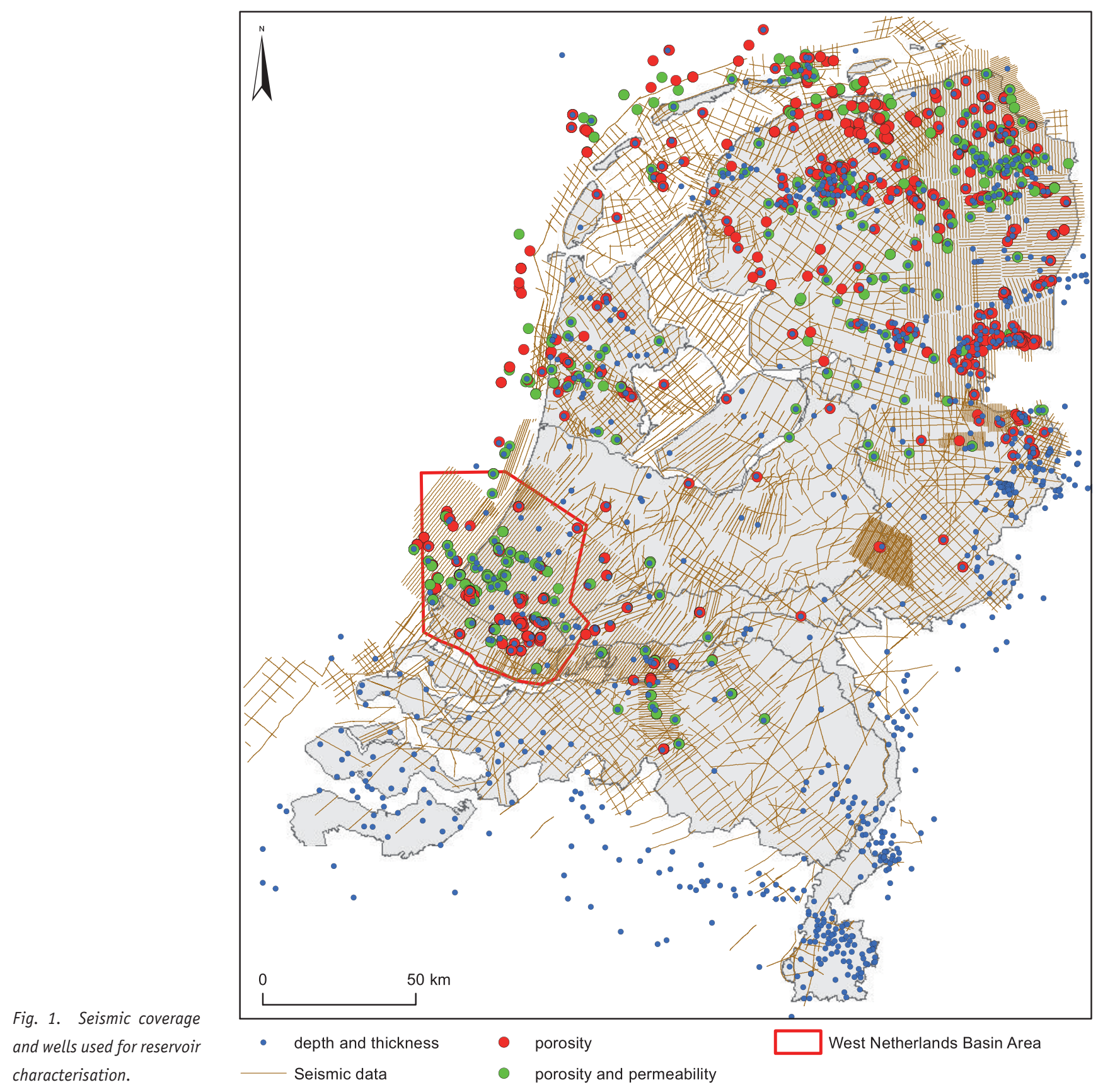



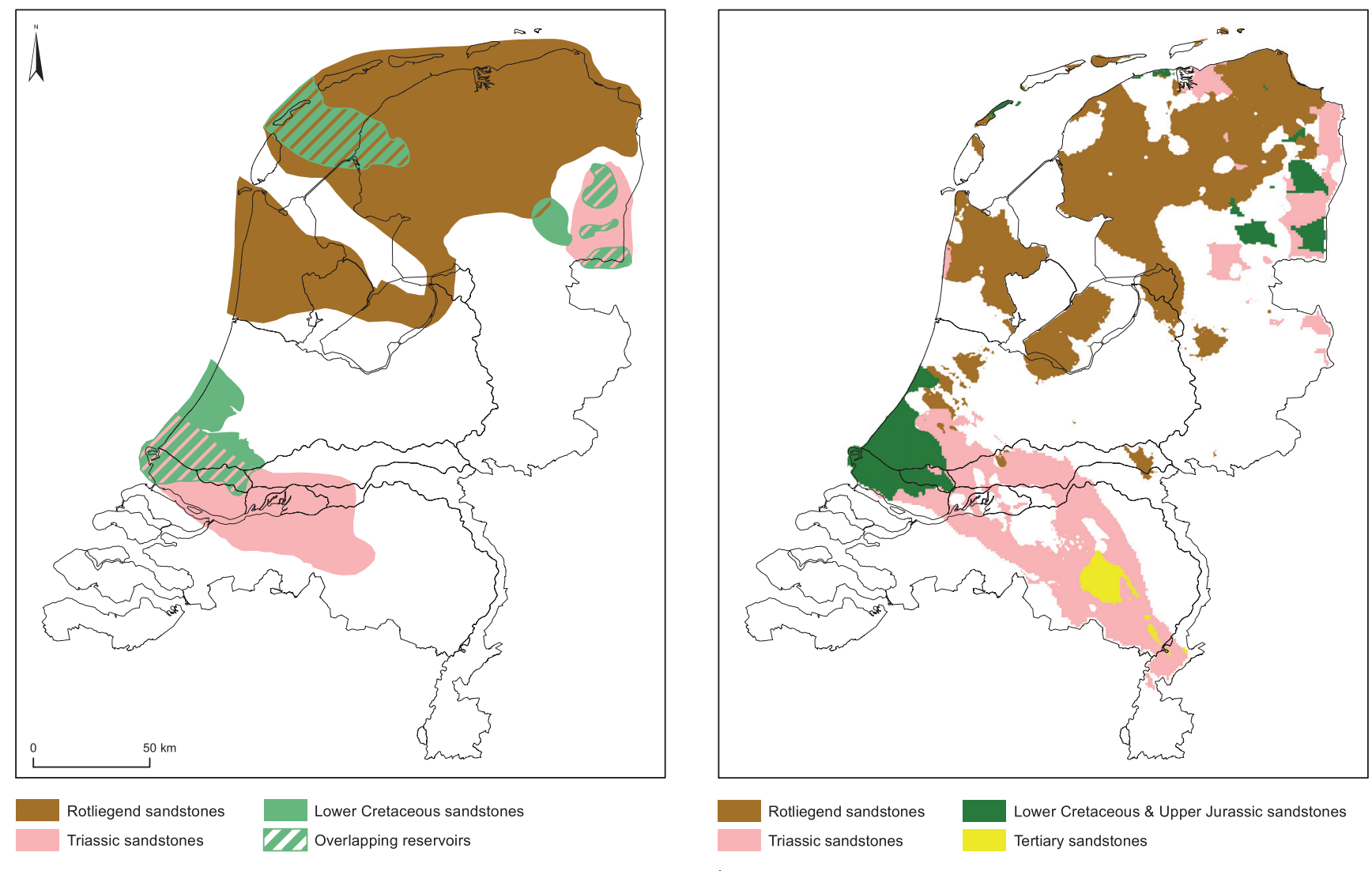

a.

$b$.

Fig. 2. Distribution of deeper aquifers with geothermal potential. a. Potential map modified after TNO-NITG (2004); b. Potential map based on ThermoGIS (Van Wees et al., this issue; Kramers et al., this issue), based on detailed geothermal aquifer characterisation.

wells have been drilled and over $72,000 \mathrm{~km}$ of seismic has been acquired for oil and gas exploration and production (Fig. 1). Most of these wells have been logged and cored in order to assess reservoir properties. 0ver 150,000 core plug measurements are available. All this data is freely accessible at the portal of Digital Information of the Dutch Subsurface (www.dinoloket.nl) and the portal of Dutch Oil and Gas Data (www.nlog.nl).

In order to incorporate all hydrocarbon exploration data on a regional scale, mapping of aquifer properties (depth, thickness, transmissivity) was performed in a newly developed workflow. This paper describes the methodology and main results of the screening of potential reservoirs.

Complementary to this study, Van Wees et al. (this issue) describes how the results of the aquifer mapping have been used as input for performance calculation and resource assessment. Kramers et al. (this issue) discusses the way the data have been included into the Dutch public geothermal information system ThermoGIS. In addition, Bonté et al. (this issue) analyse the mapping of subsurface temperatures.

The paper is subdivided into three sections. In the first part we describe the way aquifers have been selected for mapping and place these in a context of earlier assessments of geothermal potential. In the second part we explain the methodology for the geothermal characterisation of aquifers including depth and thickness, porosity, permeability and transmissivity and explain how we assessed both expected values as well as uncertainty. In addition, we also discuss the effect of burial anomalies which can have an important influence on porosity interpolations and inferences on permeability and transmissivity. In the last section we briefly present the most important results of the aquifer mapping and their geothermal potential.

\section{Aquifer selection}

Geothermal water production and reinjection requires highly permeable zones in the subsurface. Most likely candidates are aquifers. Starting point in geothermal potential evaluation was therefore to select possible candidate aquifers.

In this study all known aquifers in the Cenozoic, Mesozoic and Permian sequence have been screened in order to determine their potential for heat production. Core descriptions, core plug measurements, well log interpretations and literature study have been used. To qualify, an aquifer needs to meet the following requirements:

1. An aquifer should be distributed over a large area of at least $10 \mathrm{~km}^{2}$.

2. In line with market needs it is assumed that the initial aquifer water temperature should be at least of $40{ }^{\circ} \mathrm{C}$. This corresponds to a minimum depth of $1000 \mathrm{~m}$, assuming a temperature gradient of $30^{\circ} \mathrm{C} / \mathrm{km}$. 
3. An aquifer should have a minimum thickness of $20 \mathrm{~m}$ over a significant portion of the distribution area. Aquifers thinner than $20 \mathrm{~m}$ are not expected to meet a minimum transmissivity of $10 \mathrm{Dm}$, as defined as a cut-off by Kramers et al. (this issue).

This approach resulted in a selection of 20 aquifers (Table 1 ). Compared to the potential aquifer map presented in Lokhorst \& Wong (2007; Fig. 2a), Cenozoic aquifers are now incorporated. The workflow process of mapping geothermal transmissivity for these 20 aquifers has resulted in a significantly more detailed extend of potential aquifers, outlined in Fig. $2 \mathrm{~b}$.

\section{Reservoir characterisation}

In this paper we describe a regional reservoir characterisation workflow which takes existing 3D subsurface models, core plug data and log data from wells as input. The 3D models of the subsurface provided the boundaries of the main stratigraphic groups (e.g. base Jurassic; TNO-NITG, 2004; Duin et al., 2006).
The number of published studies on flow properties of reservoirs is rather limited, because it was mainly done in-house by oil companies. Wells and associated exploration studies have not been uniformly distributed throughout the area but focussed on structurally high areas and in areas with proven hydrocarbon plays. So, despite hydrocarbon and geothermal exploration target similar stratigraphic levels, the spatial data density is heterogeneous.

The process of mapping (maximum burial) depth and thickness of aquifers is presented first. Subsequently, the mapping of transmissivity, which is subdivided into five process steps, is described in the sections below. The workflow predicts average values as well as underlying uncertainty.

The workflow steps (Fig. 3) rely on a number of key assumptions:

a. An average value for permeability is assumed for individual aquifers. The mapped thickness of the aquifer is not further differentiated to net pay zones through a cut-off value in permeability. Although it can be argued that average values

Table 1. List of aquifers included in ThermoGIS.

\begin{tabular}{|c|c|c|c|c|c|}
\hline Stratigraphic unit & Stratigraphic Group & $\begin{array}{l}\text { ThermoGIS } \\
\text { group code }\end{array}$ & $\begin{array}{l}\text { Stratigraphic } \\
\text { Formation }\end{array}$ & Stratigraphic Member & $\begin{array}{l}\text { ThermoGIS } \\
\text { member code }\end{array}$ \\
\hline \multirow[t]{8}{*}{ North Sea } & Lower North Sea & $\mathrm{N}$ & Veldhoven & Voort & NMVFV \\
\hline & & & Rupel & Steensel & NMRFT \\
\hline & & & & Vessem & NMRFV \\
\hline & & & Dongen & Basal Dongen Sand & NLFFD \\
\hline & & & Landen & Reusel & NLLFR \\
\hline & & & & Heers Sand & NLLFS \\
\hline & & & & Swalmen & NLLFL \\
\hline & & & & $\begin{array}{l}\text { Swalmen, Heers Sand, Reusel, Basal Dongen Sand, } \\
\text { Vessem, Steensel, Voort }\end{array}$ & N-Stacked \\
\hline \multirow[t]{4}{*}{ Lower Cretaceous } & Rijnland & $\mathrm{KN}$ & Vlieland Sst. & Friesland Sst. & KNNSF \\
\hline & & & & Gildehaus Sst. & KNNSG \\
\hline & & & & Bentheim Sst. & KNNSP \\
\hline & & & & $\begin{array}{l}\text { Rijswijk Sst., Berkel Sst., IJsselmonde Sst., } \\
\text { De Lier Sst. stacked }\end{array}$ & KNWNB \\
\hline \multirow[t]{2}{*}{ Jurassic } & Schieland & S & Nieuwerkerk & Delft Sst. & SLDND \\
\hline & & & & Jurassic \& Lower Cretaceous & JK-Stacked \\
\hline \multirow[t]{9}{*}{ Triassic } & Upper Germanic Triassic & TR & Röt & Röt Fringe Sst. & RNROF \\
\hline & Lower Germanic Triassic & & Hardegsen & & RBMH \\
\hline & & & Detfurth & Upper Detfurth Sst. & RBMDU \\
\hline & & & & Lower Detfurth Sst. & RBMDL \\
\hline & & & Volpriehausen & Upper Volpriehausen Sst. & RBMVU \\
\hline & & & & Lower Volpriehausen Sst. & RBMVL \\
\hline & & & & Lower Volpriehausen Sst., Upper & TR-Stacked \\
\hline & & & & Volpriehausen Sst., Lower Detfurth Sst., & \\
\hline & & & & Upper Detfurth Sst., Hardegsen Fm., Röt Fringe Sst. & \\
\hline \multirow[t]{3}{*}{ Permian } & Upper Rotliegend & RO & Slochteren & (Upper) Slochteren & ROSLU \& ROSL \\
\hline & & & & Lower Slochteren & ROSLL \\
\hline & & & & (Upper) Slochteren and Lower Slochteren & R0-Stacked \\
\hline
\end{tabular}




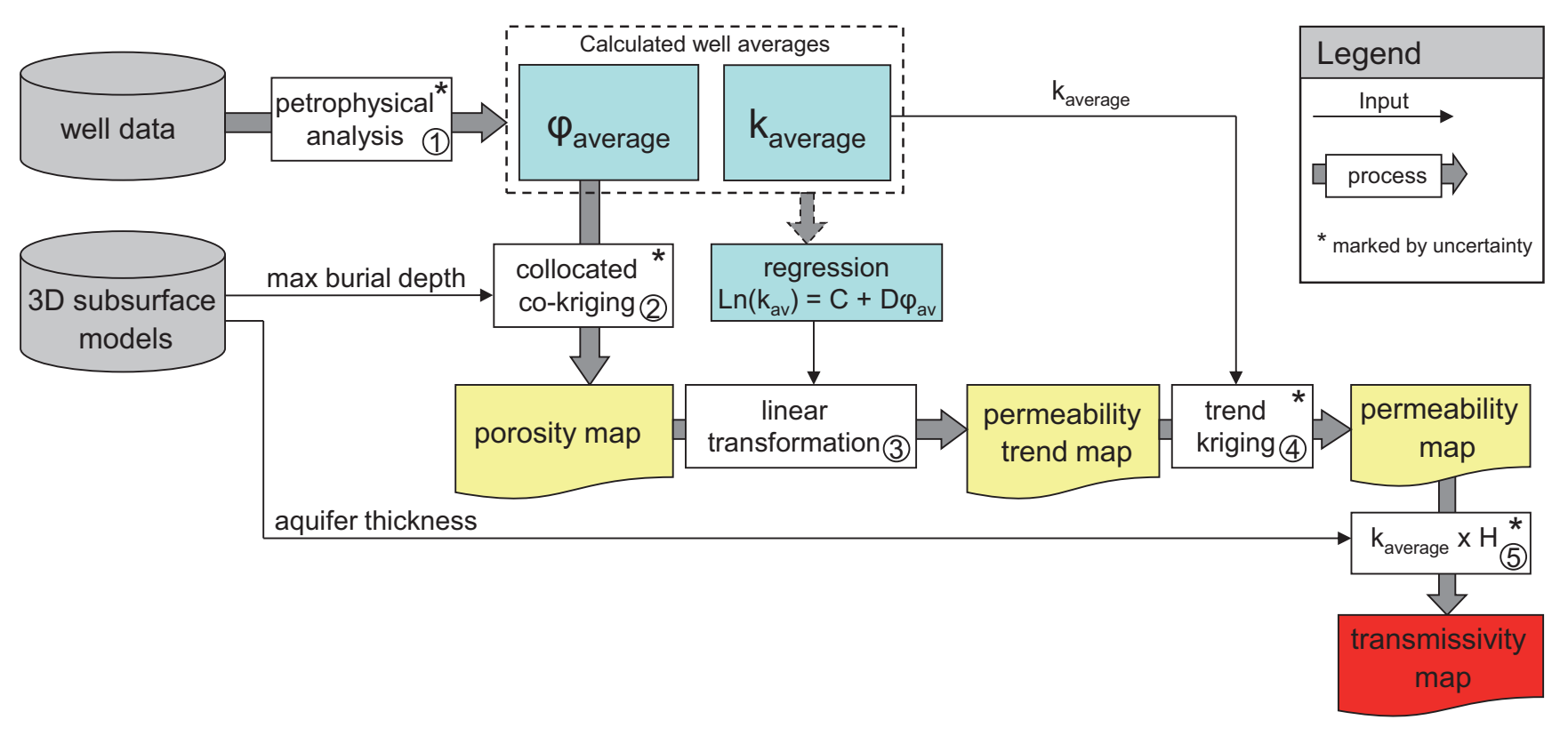

Fig. 3. Workflow for geothermal characterisation. The workflow takes 3D subsurface models and well data as input. The process for mapping transmissivity is denoted by five process steps which are discussed in the text. $\varphi$ stands for porosity and $k$ for permeability. Processes marked with * take uncertainty into account.

of permeability would be higher when net pay zones are taken into account, the transmissivity of the aquifer will not change as the thickness is proportionally reduced. A drawback of averaging permeability is the masking of possible preferential flow through high perm zones. This will increase uncertainty in doublet lifetime regarding to breakthrough of cold injection water.

b. It is assumed that the logarithm of permeability (ln k) and the porosity $(\varphi)$ hold a linear relationship. This relationship is supported by core data (Fig. 4) and is widely used in basin and reservoir modelling (e.g. Hantschel \& Kauerauf, 2009), although it is important to note that there is considerable uncertainty as permeability strongly depends on lithofacies and cementation caused by diagenetic processes (e.g. Pape et al., 1999). Consequently, in the absence of permeability data, porosity is a good indicator of permeability. This type of linear relationship is used on a well basis to transform a porosity log into a permeability log, and is also used to construct a predictive relationship for average permeability from average porosity of the aquifer.

c. Commonly it is assumed that porosity decreases with depth as a result of mechanical compaction. Porosity depth curves have been widely adopted in basin modelling to predict decrease of porosity with depth (e.g. Bond \& Kominz, 1984; Allen \& Allen, 2005) and hence permeability of sediments (Hantschel \& Kauerauf, 2009). Burial depth should therefore be used in spatial interpolation either through co-kriging or adopting a porosity-depth curve. Here we adopt data driven co-kriging, as porosity depth curves strongly depend on lithology and are marked by significant uncertainty (Van Balen et al., 2000; Van Wees et al., 2009) which is hard to constrain to the porosity data in the wells.
Fig. 4. Linear relationship between porosity and the logarithm of permeability measurements observed in core plugs.

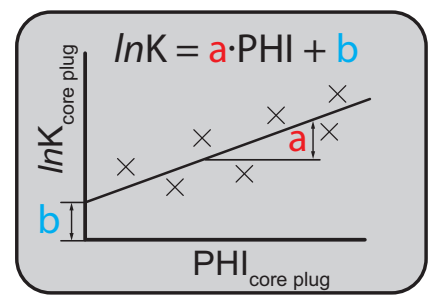

d. Mechanical compaction can be higher than expected regarding the present-day depth if rocks have been buried more deeply in the past. If significant (e.g. larger than few hundred meters), the excess burial or so called burial anomaly, should be taken into account in the spatial interpolation of porosity. Burial anomalies are caused by erosional events, bringing deeply buried rocks closer to the surface. However if the erosion is followed by burial which is equal in magnitude or higher than the erosion, then the burial anomaly is lost. In the Netherlands burial anomalies can be significant over large regions (e.g. Worum, 2004; Nelskamp \& Verweij, 2012) and have been taken into account in porosity estimation through co-kriging with the reconstructed maximum burial depth instead of the observed burial.

\section{Depth and thickness}

Aquifer depth and thickness have been mapped by 2D geostatistical interpolation techniques using the existing mapped major stratigraphic horizons of the onshore Netherlands (TNONITG, 2004) as a geometrical framework.

The first step included a revision of the geometrical framework using all publicly available wells (Fig. 1). The depth of the horizons has been modified at well locations and the areas 
surrounding the well location using a kriged correction grid based on the misfit between well information and horizons. Kriging is an interpolation method where the interpolated value is a distance-weighted average of the known datapoints. The spatial correlation and accompanying variance of the data points is characterised in a variogram. The variance (uncertainty) of the interpolated value will increase as the distance to known datapoints increases.

In the second step the depth and thickness of the aquifers have been included in the geometrical framework. The extent of the aquifer is based on wells penetrating the aquifer combined with the subcrop boundaries of the main stratigraphic horizons. Since the top and bottom of the mapped aquifers have to honour the geometrical framework and therefore needs truncation in some cases, structurally controlled jumps in thickness occur (Fig. 5).

Uncertainty (in seismic interpretation, velocity modelling and data density) has not been taken into account in the mapping of the depth of the aquifers (this has been done for the main stratigraphic horizons, see Kombrink et al., this issue). Uncertainty in thickness has been calculated based on the geostatistical analyses of thickness of the aquifers in the wells only. It is assumed that this uncertainty is sufficient for capturing large wavelength effects. However in some structural settings, where aquifers have been differentially eroded in fault bounded compartments, this may not be sufficient. In the workflow presented here, the latter component of uncertainty has not been taken into account. Figure 6 shows the thickness and the related uncertainty of the Rotliegend joint Slochteren and Upper Slochteren Members. Please note that uncertainty in thickness (standard deviation) can be considerable and in some cases even exceeds the mapped thickness. In that case the probability of not finding the aquifer at all is $15 \%$ (equivalent of one standard deviation).

\section{High resolution 3D models for the West Netherlands Basin}

From 2005 onwards geothermal exploration has been pursued with mixed success in Lower Cretaceous sandstones in the West

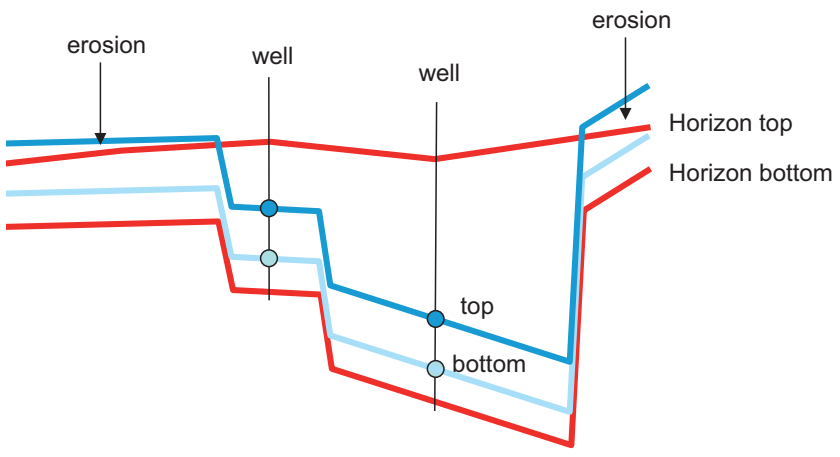

Fig. 5. Principle of erosion by the skeleton (red) of the geostatistically determined thickness of the aquifers from wells (blue).
Netherlands Basin (Fig. 1). Various doublets have been drilled which produce sufficient quantities of geothermal heat. Due to the strongly discontinuous spatial distribution of the LowerCretaceous members in the West Netherlands Basin, a detailed 3D facies model has been developed in this region instead of mapping each aquifer separately. This model (see Vis et al., 2010 for further details) replaces earlier layer-based aquifer interpretations of the Rijswijk, Berkel, IJsselmonde and De Lier Members (Van Adrichem Boogaert \& Kouwe, 1993). Instead of interpreting top and bottoms of sandstone layers the modelled volume is represented by a 3D raster or so called voxelised volume which has been subsequently populated with different facies including marine and fluvial sands and shales, constrained by well information. To represent uncertainty, 50 equally probable model realisations were run. From these stochastic realisations, average net sand thickness, depth and standard deviation in net sand thickness could be determined.

\section{Transmissivity}

The first step in mapping the transmissivity is the determination of average porosity and the average permeability, as input for the generation of average porosity maps and as input for a predictive trend of average porosity and permeability (Fig. 3, process 1). To obtain average porosity and permeability, an extensive dataset of approximately 12,000 porosity and permeability core plug values and over 650 logs of onshore wells were used. Table 2 summarises the data used for the different aquifer intervals. The data listed is digitally available from www.nlog.nl (status: July 2011) and corresponds to about 50\% of the available data. Complementary to digital available data, compiled results from reports on petrophysical analysis from various sources including public geothermal studies have been used.

\section{Porosity}

For each aquifer the average porosity was calculated for all wells with available digital porosity logs and core plug data. The standard oil \& gas petrophysical workflow was used for porosity determination (Schlumberger, 1991).

When porosity logs are available, the porosity log of the total aquifer interval was calculated on the basis of bulk density log (RHOB) and/or the neutron porosity log if available (NPHI). When only bulk density logs were available, porosity logs were calculated following equation:

$$
\text { PHI }=\frac{\rho_{\text {grain }}-\rho_{\text {bulk }(\text { RHOB })}}{\rho_{\text {grain }}-\rho_{\text {fluid }}}
$$

where grain density $\rho_{\text {grain }}$ is obtained from core plug measurements and fluid density $\rho_{\text {fluid }}$ was assumed $1.1 \mathrm{~g} / \mathrm{cm}^{3}$, the average density of salt and fresh water. When neutron logs were available, they have been used with a correction for the 


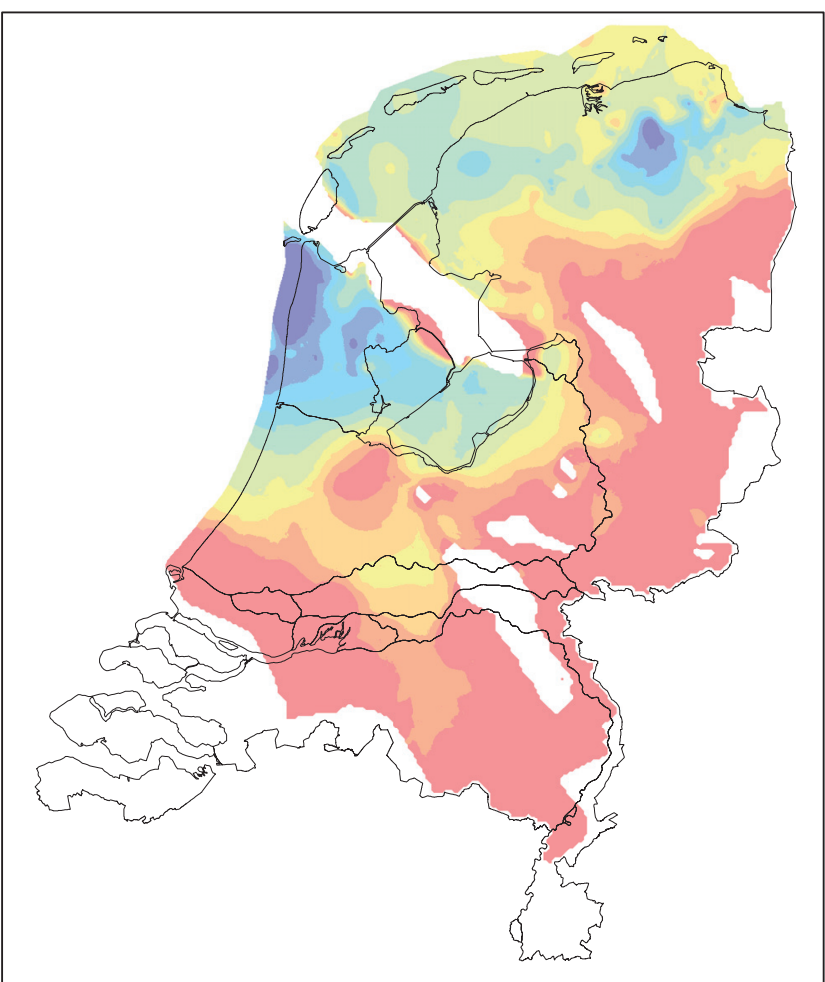

Thickness (m)

\begin{tabular}{l|l}
$<25$ & $125-150$ \\
$25-50$ & $150-175$ \\
$50-75$ & $175-200$ \\
$75-100$ & $200-225$ \\
$100-125$ & $>225$
\end{tabular}

Fig. 6a. Thickness with accompanied uncertainty (b) of the joint Slochteren and Upper Slochteren members.

fact that neutron logs represent porosity based on carbonate rock (Eq. 3):

$$
\mathrm{PHI}=\mathrm{NPHI}+0.045
$$

If bulk density and neutron logs were available, both aforementioned methods were used and averaged. If core plug measurements were available, the calculated porosity logs were shifted to fit the core-porosity measurements. The logs have been averaged arithmetically to average aquifer porosity. When only core measurements were available the average aquifer porosity has been assumed equal to the average of the core values.

\section{Permeability}

Permeability is directly derived from porosity in the wells. For this conversion, a linear relation between porosity and the logarithm of the permeability from core plug measurements has been used. This relation was determined by a least-square regression on the core plug measurements (Fig. 4). For each aquifer interval, calculated porosity logs could be transformed
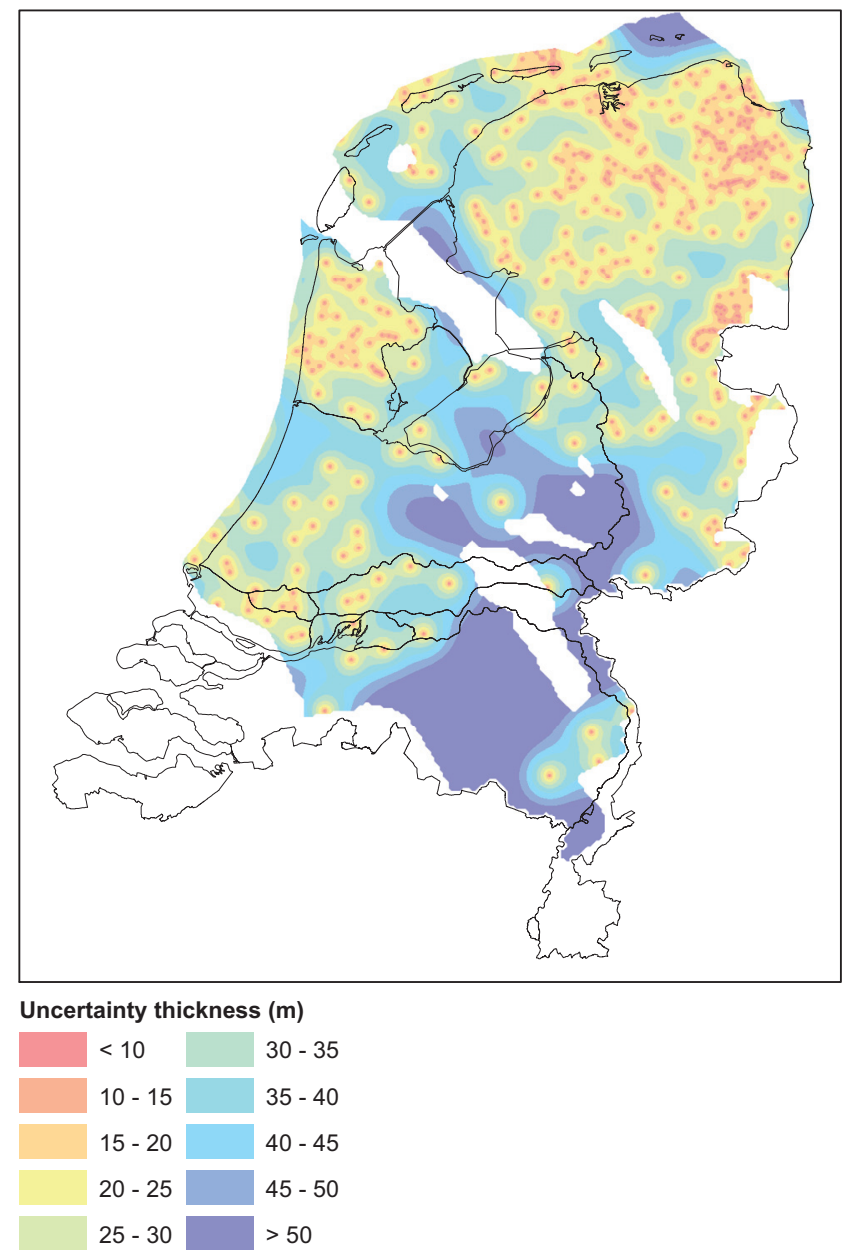

b. to permeability logs if core plug measurements were available and a porosity-permeability relation could be derived. As core plug measurements are not available in each well, this resulted in a much smaller permeability dataset compared to the porosity dataset. The logs have been averaged arithmetically to an average aquifer (horizontal) permeability. When only core measurements were available, the average permeability has been assumed equal to the average of the core values.

\section{Average porosity - average permeability trend}

In a final step the trend of average porosity and average permeability has been determined to convert a porosity map into trend permeability map using the following equation:

$$
\ln \left(\mathrm{k}_{\text {average }}\right)=\mathrm{C}+\mathrm{D} \phi_{\text {average }}
$$

where $\mathrm{C}$ and $\mathrm{D}$ represent the intercept and slope respectively of the trend line of average porosity and the logarithm of average permeability. In a later process a correction was applied to account for the deviations of the calculated average permeability from the trend line, and the observed permeability at well loca- 
Table 2. List of well data input to petrophysical analysis for the studied aquifers. The well columns indicate the total amount of wells with porosity/ permeability data penetrating the aquifer, the number of wells with porosity logs and the number of wells with core measurements. The $\varphi$ and $k$-average (digital) columns indicate the number of average $\varphi$ and $k$ data points, subdivided based on available source data (only from core data, only from log data, both core and log data). The remaining columns denote the number of wells were literature data was used. Entries marked with * indicate that $\varphi$ was based on a compaction (porosity-depth) curve.

\begin{tabular}{|c|c|c|c|c|c|c|c|c|c|c|c|c|}
\hline \multirow[t]{2}{*}{ Aquifer } & \multicolumn{4}{|l|}{ Well } & \multicolumn{3}{|c|}{$\varphi$-average(digital) } & \multicolumn{3}{|c|}{ k-average (digital) } & \multirow{2}{*}{$\frac{\varphi \text {-average }}{\text { Literature }}$} & \multirow{2}{*}{$\begin{array}{l}\text { k-average } \\
\text { Literature }\end{array}$} \\
\hline & Total & Logs & $\phi$-core & k-core & Cores & Logs & Both & Cores & Logs & Both & & \\
\hline ROSLU \& ROSL & 515 & 366 & 227 & 222 & 116 & 255 & 111 & 117 & 0 & 105 & 42 & 0 \\
\hline ROSLL & 73 & 67 & 17 & 17 & 4 & 54 & 13 & 4 & 0 & 13 & 8 & 0 \\
\hline RBMVL & 186 & 173 & 18 & 15 & 9 & 164 & 9 & 10 & 0 & 5 & 1 & 0 \\
\hline RBMVU & 49 & 44 & 12 & 11 & 3 & 35 & 9 & 2 & 0 & 9 & 2 & 0 \\
\hline RBMDL & 104 & 96 & 18 & 16 & 5 & 83 & 13 & 9 & 0 & 7 & 2 & 0 \\
\hline RBMDU & 28 & 22 & 8 & 7 & 3 & 17 & 5 & 4 & 0 & 3 & 3 & 0 \\
\hline $\mathrm{RBMH}$ & 55 & 46 & 22 & 21 & 7 & 31 & 15 & 8 & 0 & 13 & 5 & 0 \\
\hline RNROF & 60 & 43 & 34 & 32 & 14 & 23 & 20 & 14 & 0 & 18 & 5 & 0 \\
\hline SLDND & 7 & 5 & 2 & 2 & 2 & 5 & 0 & 2 & 0 & 0 & 0 & 2 \\
\hline KNWNB & 167 & 95 & 72 & 72 & 72 & 76 & 19 & 72 & 0 & 19 & 0 & 0 \\
\hline KNNSF & 97 & 78 & 35 & 32 & 18 & 61 & 17 & 20 & 0 & 12 & 0 & 0 \\
\hline KNNSP & 226 & 155 & 77 & 72 & 67 & 145 & 10 & 66 & 0 & 6 & 0 & 0 \\
\hline KNNSG & 72 & 62 & 12 & 11 & 10 & 60 & 2 & 9 & 0 & 2 & 0 & 0 \\
\hline NLLFL & 0 & 0 & 0 & 0 & 0 & 0 & 0 & 0 & 0 & 0 & 0 * & 0 \\
\hline NLLFS & 0 & 0 & 0 & 0 & 0 & 0 & 0 & 0 & 0 & 0 & 0 * & 0 \\
\hline NLLFR & 0 & 0 & 0 & 0 & 0 & 0 & 0 & 0 & 0 & 0 & 0 * & 0 \\
\hline NLFFD & 2 & 0 & 2 & 1 & 2 & 0 & 0 & 1 & 0 & 0 & 0 * & 0 \\
\hline NMRFV & 1 & 0 & 1 & 1 & 1 & 0 & 0 & 1 & 0 & 0 & 0 * & 0 \\
\hline NMRFT & 0 & 0 & 0 & 0 & 0 & 0 & 0 & 0 & 0 & 0 & 0 * & 0 \\
\hline NMVFV & 4 & 0 & 3 & 3 & 3 & 0 & 0 & 3 & 0 & 0 & 0 * & 2 \\
\hline
\end{tabular}

tions. Figure 7 shows a comparison of the porosity-permeability relationship calculated using well-log derived versus corederived averages from a dataset of Rotliegend aquifers. This figure clearly demonstrates that when relying on core data only, high permeable streaks can be overlooked which subsequently results in too low a permeability prediction. However the average core porosity values still agree well with the averages from the logs. The dataset used for determination of the average trend of log-derived average porosity and permeability was supplemented with averages from core measurements for wells where log-derived averages were missing. Table 3 lists the $C$ and $D$ intercept and slope values for the aquifers. It is also indicated when core averages of permeability have been used for the trend line.

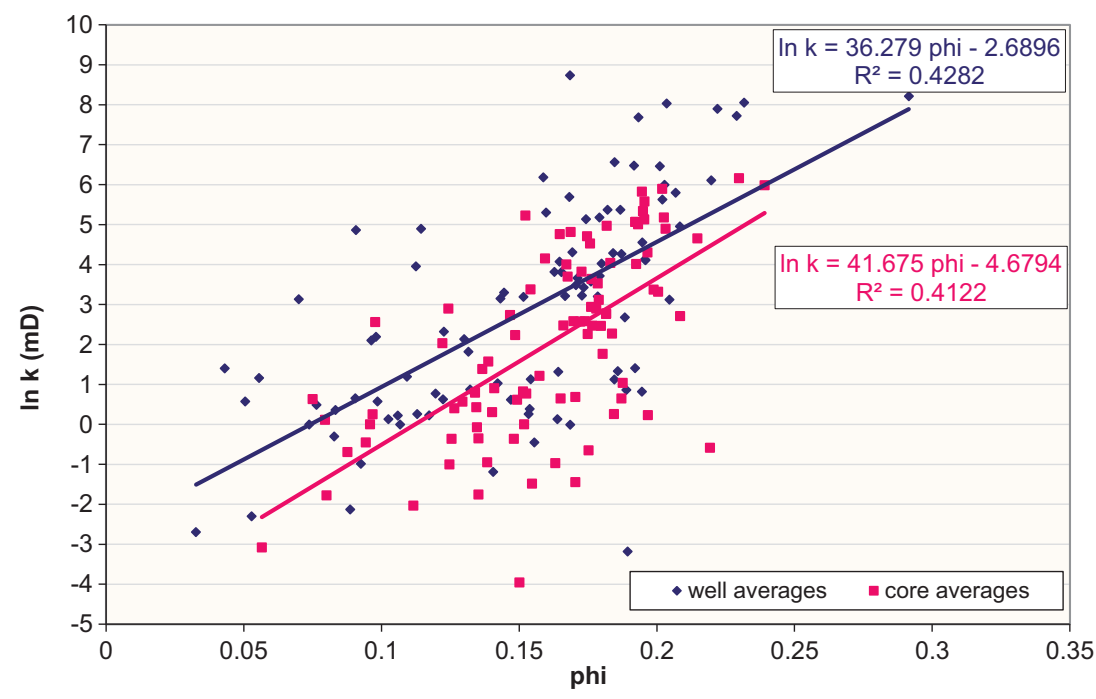

Fig. 7. Relationship between average porosity and average permeability values in Rotliegend aquifers based on both log and core data. Using well log averages results in significantly higher permeability (3-10 times) than using core averages. 
Table 3. Intercept (C) and slope (D) of average porosity and average natural logarithm of permeability $(m D)$ of the different aquifers. The table lists the amount of wells with logs and/or cores used for the trend and the number of wells with only core data. Entries marked with * denote that literature values were used. For the KNWNB aquifer, different modelling approach was chosen (see Vis et al., 2010).

\begin{tabular}{llllll}
\hline \multirow{2}{*}{ Aquifer } & \multicolumn{2}{l}{ Regression } & & \multicolumn{2}{l}{ Data points } \\
\cline { 2 - 3 } & C & D & & Logs & Cores only \\
\hline ROSLU \& ROSL & -1.88 & 0.319 & & 105 & 116 \\
ROSLL & -2.27 & 0.288 & & 13 & 4 \\
RBMVL & -4.11 & 0.498 & & 5 & 9 \\
RBMVU & -2.82 & 0.454 & & 2 \\
RBMDL & -3.62 & 0.437 & & 7 & 5 \\
RBMDU & -1.38 & 0.330 & & 3 & 3 \\
RBMH & -4.06 & 0.539 & & 13 & 7 \\
RNROF & -0.41 & 0.298 & & 18 & 14 \\
SLDND & 0.38 & 0.202 & & 0 & 2 \\
KNWNB & - & - & & - \\
KNNSF & -2.16 & 0.198 & & 12 & 18 \\
KNNSP & -2.25 & 0.299 & & 6 \\
KNNSG & 0.06 & 0.089 & & 2 & 9 \\
NLLFL * & -1.49 & 0.242 & & 0 \\
NLLFS * & -1.49 & 0.242 & & 0 \\
NLLFR * & -1.49 & 0.242 & & 0 \\
NLFFD * & -1.49 & 0.242 & 0 & 0 \\
NMRFV * & -1.49 & 0.242 & 0 & 1 \\
NMRFT * & -1.49 & 0.242 & 0 & 0 \\
NMVFV * & -1.49 & 0.242 & 0 & 3 \\
\hline & & & & 0
\end{tabular}

\section{Burial anomaly reconstruction and porosity maps}

As mentioned before, the mapview interpolation of the average porosity was done with the collocated co-kriging method, in which the maximum burial depth as a second, collocated variable was taken into account (Fig. 3, process 2). Collocated cokriging interpolation (Xu et al., 1992) takes into account the correlation between primary data (porosity from well data) and secondary data (burial depth from well and horizon data) which is available throughout the entire model area. This means that interpolation of a porosity value away from the well location will also depend on burial depth.

In order to construct maximum burial, the excess burial or so called burial anomaly is added to the present-day burial. In the Netherlands various studies addressed burial anomalies and have shown that they can be significant over large regions (e.g. Worum, 2004; Van Dalfsen et al., 2005; Van Wees et al., 2009; Luijendijk et al., 2011; Nelskamp \& Verweij, 2012). Burial anomalies can be detected in various ways. In this paper we adopted a complementary approach to assess burial anomalies. For the structural inverted basins (De Jager, 2007), first order burial anomaly values have been determined from structural reconstruction as described in Van Wees et al. (2011). For the West Netherlands Basin and Roer Valley Basin areas more reliable erosion estimates are derived from a detailed basin model for maturity modelling, calibrated to maturity parameters (Nelskamp \& Verweij, 2012).

Major erosional phases occurred immediately after deposition of the Chalk Group (Laramide erosional phase) and the Schieland and Niedersachsen group (Late Kimmerian erosional phase). To obtain the burial anomaly, the calculated erosion maps of the Laramide and the Late Kimmerian erosional phases have been subtracted with the present day depth of respectively the base North Sea Supergroup and base Rijnland Group. These complementary models (Fig. 8) show that both types of erosion estimates largely agree with discrepancies up to $30 \%$. Sonic velocities indicate larger deviations (Van Dalfsen et al., 2005), and suggest much higher erosion and burial anomalies in many places. It is argued that these anomalies in sonic velocity may be artefacts related to differences in lithology.

Taking into account burial anomalies results in a better correlation in the porosity-depth relation (Figs 9, 10 and 11). This is particularly apparent for non-inverted basin margins where porosity well data control is sparse. Here, an increase in porosity of up to $3 \%$ and a related increase in permeability up to a factor

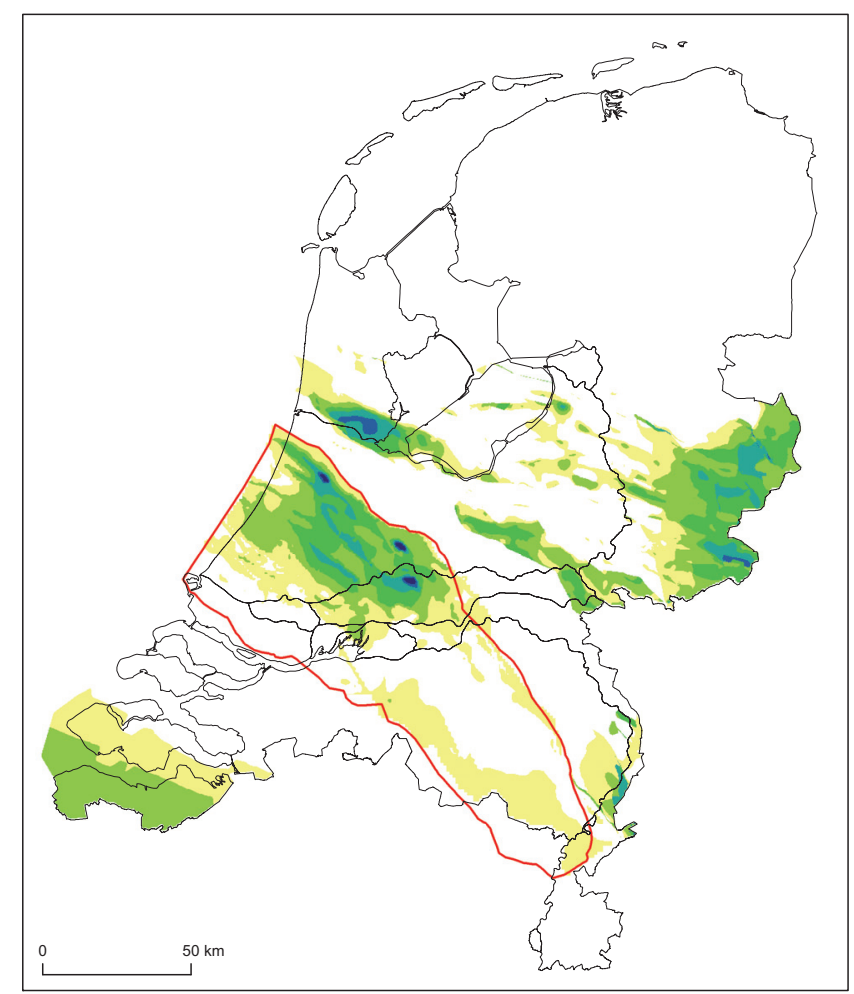

Total Burial Anomalies ( $m$ )

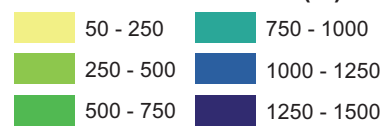

Fig. 8. Total burial anomalies in meters from the geometric reconstruction, partly complemented by results from basin modelling in the West Netherlands Basin and the Roer Valley Graben (indicated by red polygon). 


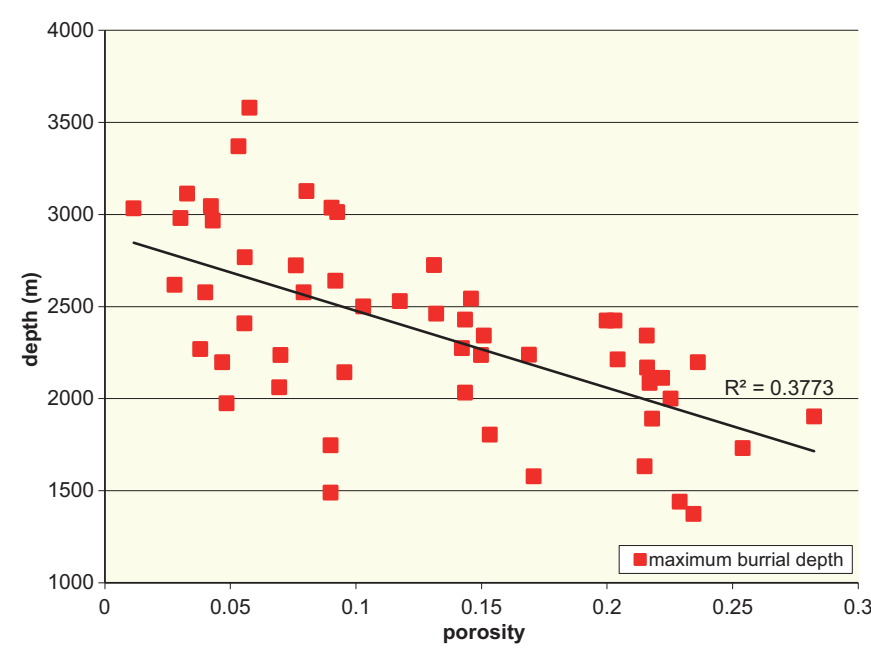

a.

Fig. 9a. Porosity-depth relationship after the correction for burial anomaly and (b) prior to correction.

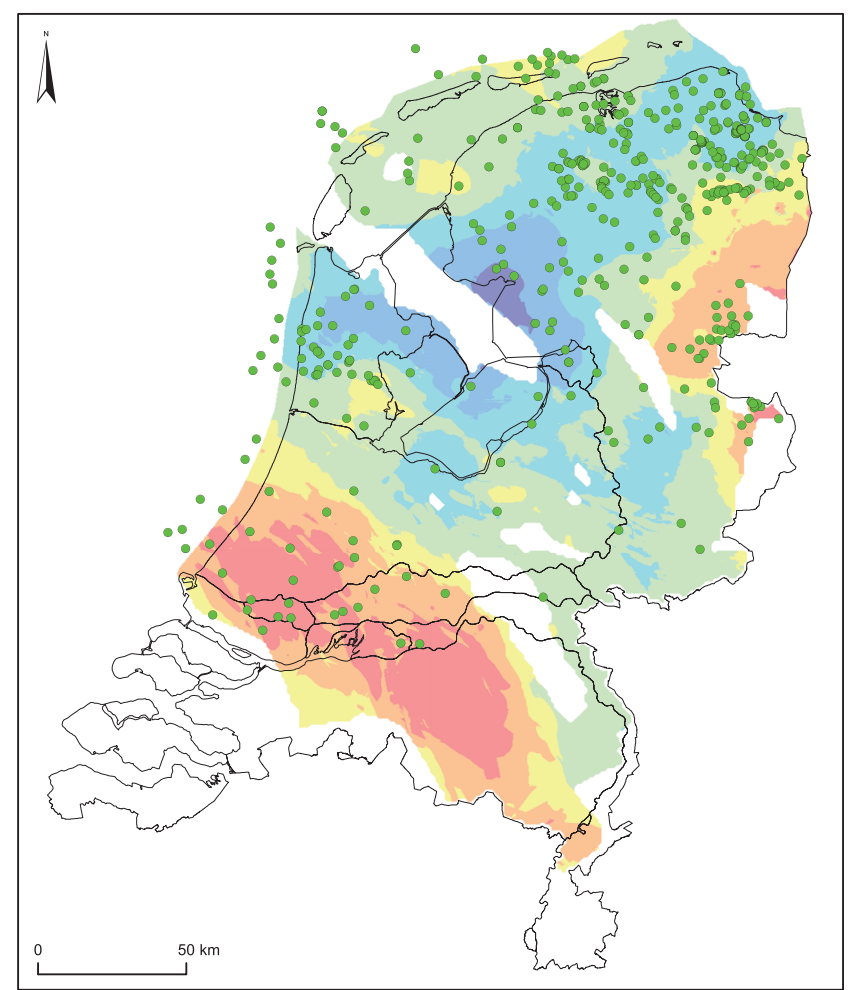

Porosity

\begin{tabular}{|l|l|l|}
\hline$<4$ & $16-20$ \\
\hline $4-8$ & $20-24$ \\
\hline $8-12$ & $>24$ \\
\hline $12-16$ & \\
\hline
\end{tabular}

a.

Fig. 10 a. Porosity map taking maximum burial into account. b. Differential map of porosity of the Rotliegend geothermal aquifer adopting maximum burial vs. adopting present day burial in the collocated co-kriging estimation. Red shaded areas are marked by increase, blue areas by decrease.

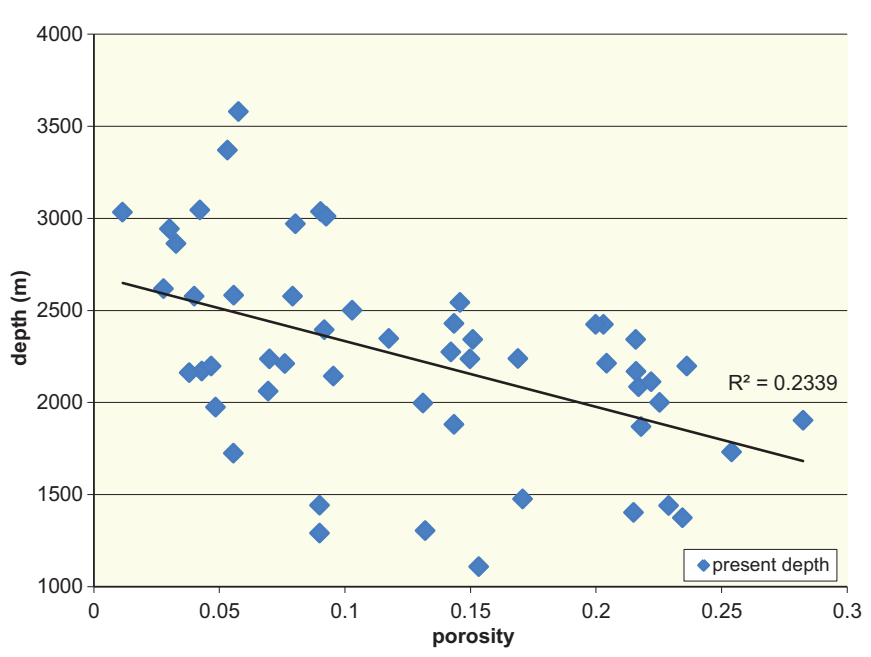

$b$.

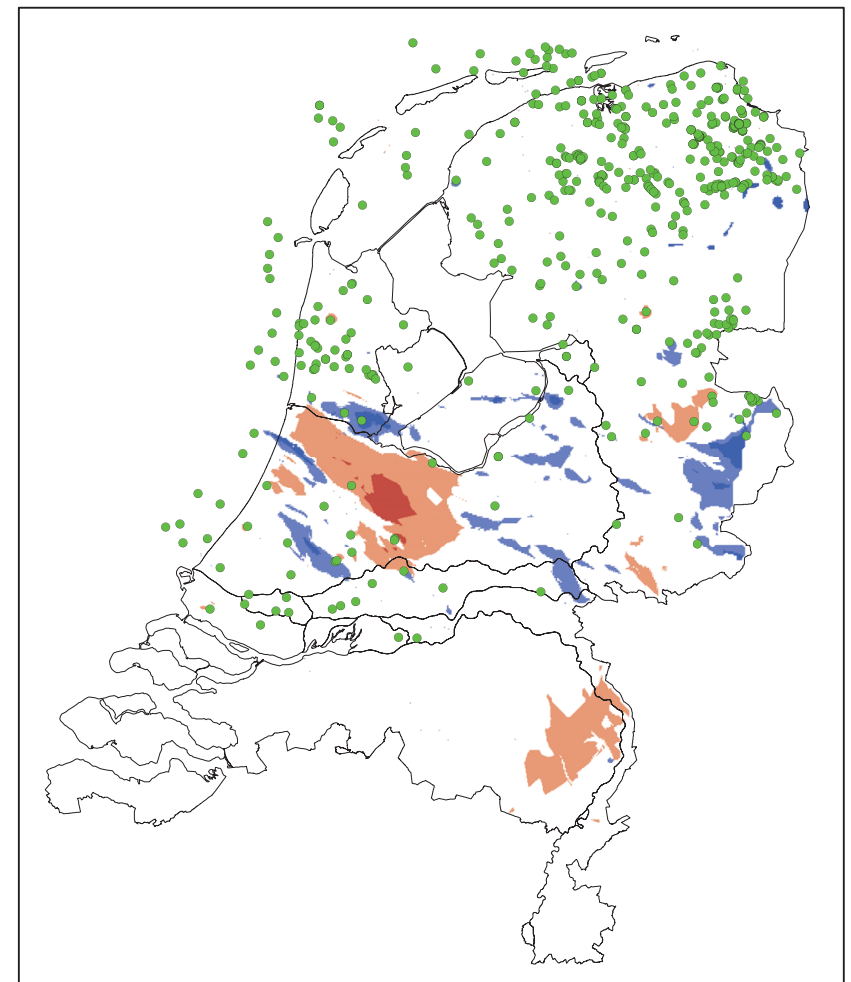

Porosity difference

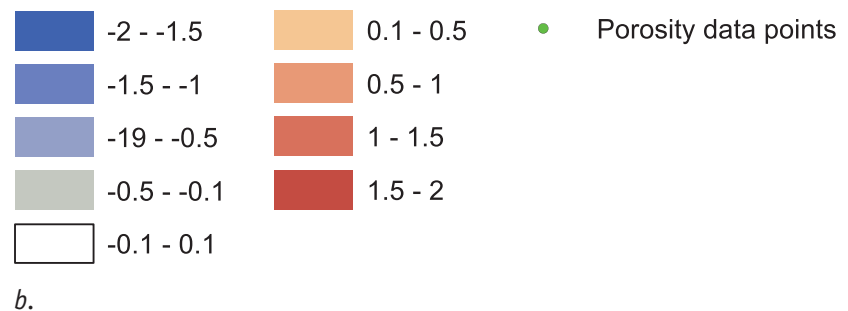




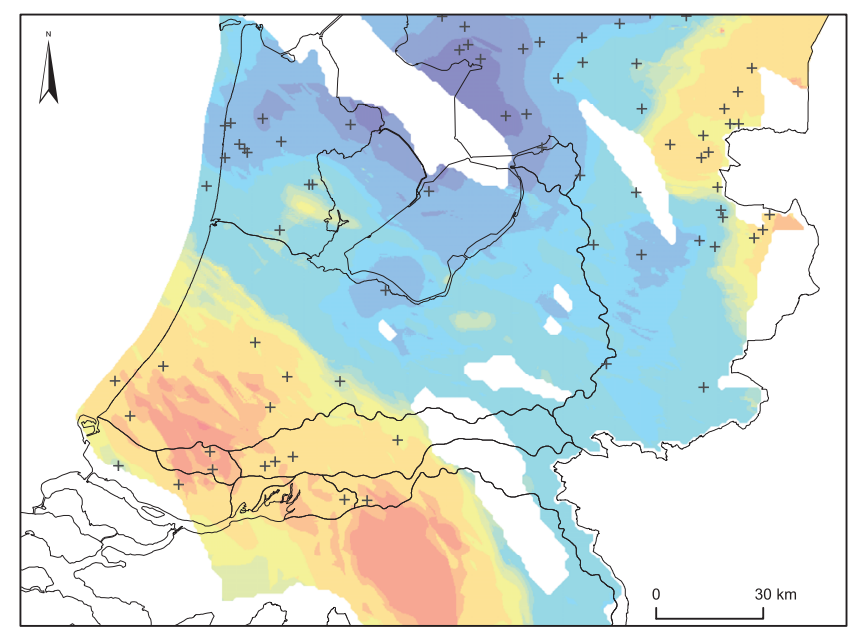

Permeability $(\mathrm{mD})$

\begin{tabular}{|l|l|l|}
\hline$<0.1$ & $4-6$ & $50-200$ \\
\hline $0.1-0.3$ & $6-8$ & $200-400$ \\
$0.3-0.5$ & $8-10$ & $>400$ \\
$0.5-2$ & $10-30$ & \\
\hline $2-4$ & $30-50$ & \\
\hline
\end{tabular}

a.

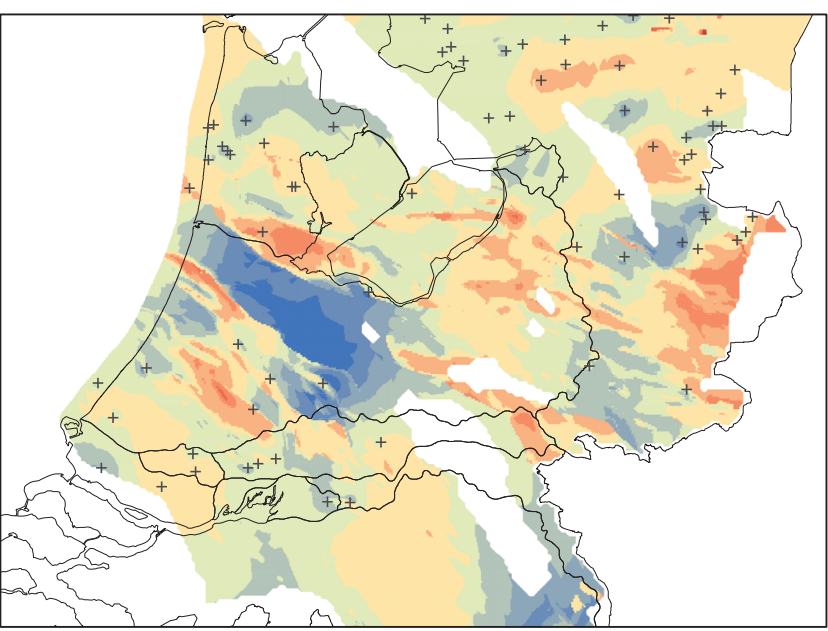

Relative permeability increase + datapoints

\begin{tabular}{|l|l|}
\hline$<0.2$ & $1-1.2$ \\
\hline $0.2-0.4$ & $1.2-1.4$ \\
\hline $0.4-0.6$ & $1.4-1.6$ \\
\hline $0.6-0.8$ & $1.6-1.8$ \\
\hline $0.8-1$ & $>1.8$ \\
\hline
\end{tabular}

$b$.

Fig. 11 a. Permeability of the Rotliegend aquifer including the effect of burial anomalies; and $b$. the ratio of corrected and uncorrected permeability.

of two were obtained. As a result, the prospectivity of basin flanks (with few data) of inverted basins (with most well data control) can be significantly enhanced by incorporating burial anomalies.

\section{Permeability and transmissivity}

Average permeability maps are constructed in two steps. First the average porosity map is converted to a permeability trend map using equation 4 (Fig. 3, process 3). Subsequently, the permeability map is obtained from trend kriging the (limited number of) kaverage data points whereby the permeability trend map is used as trend input (Fig. 3, process 4). Trend kriging interpolates the residual values of the well data, and the predictive values of the trend input map. The resulting permeability map honours the data points and follows the permeability trend when no hard permeability data is available. The transmissivity was calculated by multiplying the aquifer thickness with the obtained permeability (Fig. 3, process 5).

\section{Workflow North Sea Group aquifers}

The limited amount of data of North Sea Group aquifers did not allow the geostatistical approach as described above. A compaction based porosity estimation is proposed instead (Athy, 1930), where porosity is a function of depth:

$$
\varphi=\varphi-\mathrm{e}^{(-\mathrm{kz})}
$$

where $\varphi_{0}$ is $40 \%$ and $\mathrm{k}$ is $0.00031\left(\mathrm{~m}^{-1}\right.$; Hantschel \& Kauerauf, 2009). Figure 12 shows the porosity estimation and the data available. The compaction curve overestimates the porosity at depth below $1 \mathrm{~km}$. Permeability was estimated based on a fixed porosity-permeability relation (Eq. 4, Table 3). Parameters of this relation were derived from a previous characterisation study

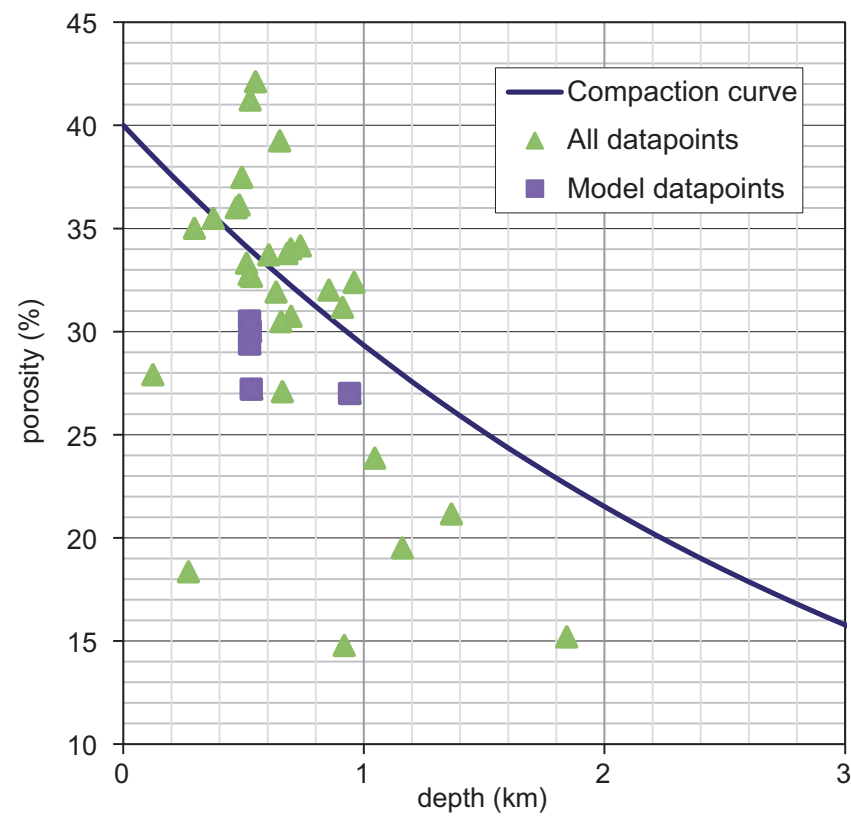

Fig. 12. Porosity estimation based on compaction (solid line) compared to data used in the modelling workflow (purple). Green data represent all available porosity data (on and offshore) of North Sea Group aquifers that were not included in the aquifer selection. 
of the Roer Valley Graben (Wiers, 2001). The resulting transmissivity for the North Sea Group is a first estimate and should be used with care, given the limited data available.

\section{Uncertainty}

The mapping workflow for deriving transmissivity did not incorporate the effect of uncertainties. For uncertainty assessment, the following assumptions have been made:

a. Porosity is normally distributed.

b. The uncertainty of the calculated average porosity at the wells is dependent on the data source. Uncertainty of log derived porosity is approximately $5 \%$. This figure reflects the uncertainty related to fluid and grain density and composition. Average porosity based only on core measurements comprises a very limited part of the reservoir rock which causes the uncertainty to be higher. Comparison between core and log averages of the Rotliegend dataset (Fig. 7) show an uncertainty of approximately $10 \%$ for porosity derived from core measurements only. Average values extracted from literature were based on full petrophysical analysis and therefore uncertainty was assumed $3 \%$.

c. Permeability is log-normally distributed.
The uncertainty of the interpolation of the porosity datapoints is expressed as the standard deviation as a result from kriging interpolation. The variogram is leading; the uncertainty at the well position is incorporated in the variogram. The standard deviation of the permeability is given by the standard deviation of the permeability trend (expressed as function of $\varphi_{S D}$ and slope D (Eq. 4)) and the standard deviation (SD) of the permeability kriging ( $k_{\text {average }}$ ) SD as expressed in equation 6:

$$
\ln \left(\mathrm{k}_{\text {average }}\right)_{S D}=\sqrt{\left.\left(\mathrm{D} \varphi_{\mathrm{SD}}\right)^{2}+\ln \left(\mathrm{k}_{\text {average }}\right)_{\text {Kriging-SD }}\right)^{2}}
$$

The transmissivity distribution has been generated through Monte Carlo sampling, assuming a lognormal distribution for $\mathrm{k}$, and a normal distribution for $\mathrm{H}$ (aquifer thickness). Monte Carlo sampling generates a new distribution by multiplying random picked samples from both $\mathrm{k}$ and $\mathrm{H}$ distributions. This procedure is repeated 1000 times to generate the new transmissivity distribution. From this distribution values for the different probability confidence levels (P10, P30, P50, P70 and P90) have been extracted at each location and have been used for map results in ThermoGIS (Kramers et al., this issue). The modal P50 values of permeability correspond to the permeability results of equation 4. The map difference of transmissivity from

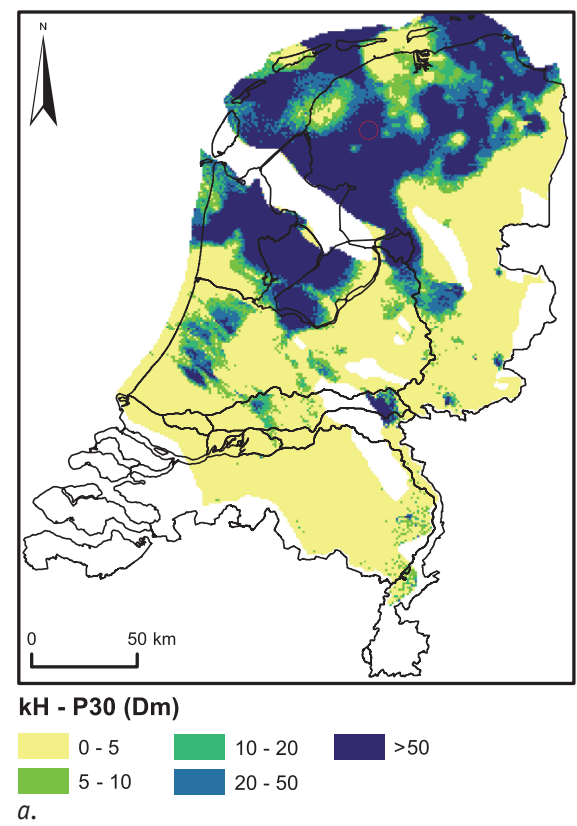

Fig. 13. Probability distribution of the transmissivity of the Rotliegend aquifer, expressed in P30 (a) P50 (b) and P70 (c) maps. The expectation curve based Monte Carlo sampling is shown for a specific location (red circle).
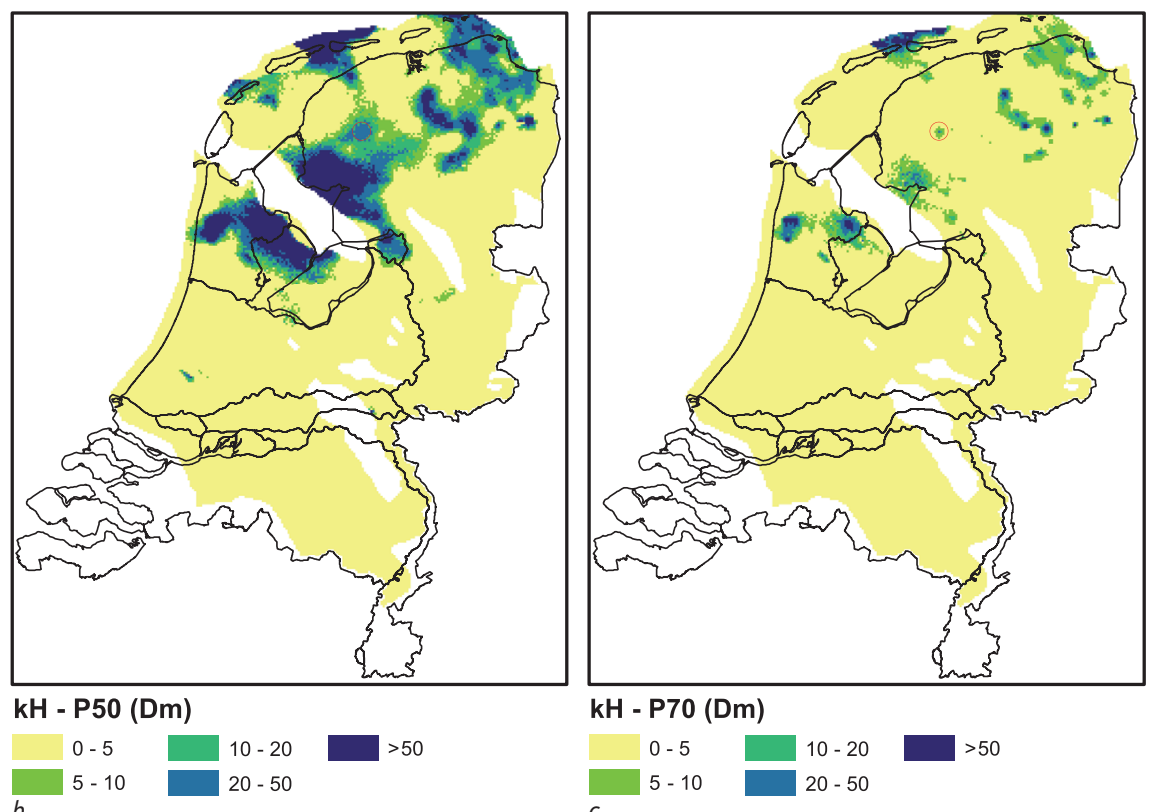

c.

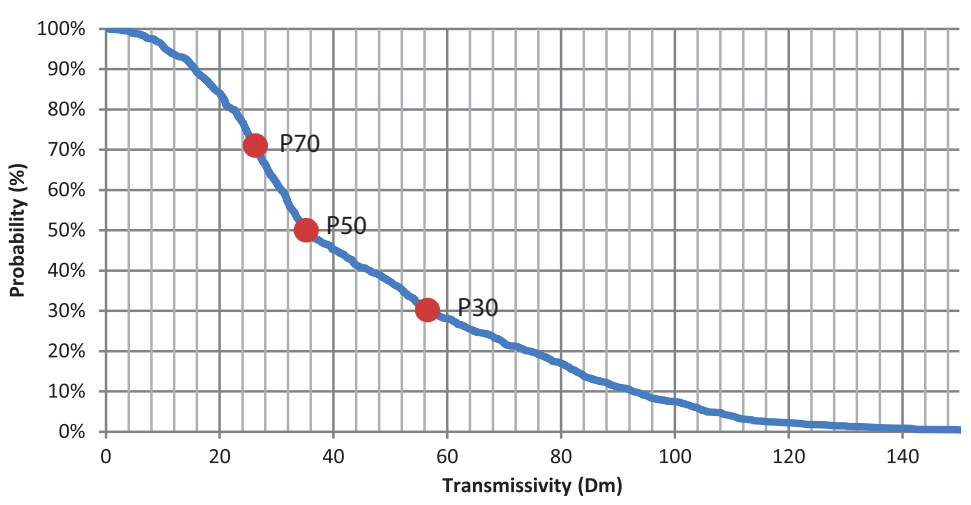


P90 to P50 and the expectation curve at a particular location (Fig. 13) typically shows variations of an order of magnitude, demonstrating the profound impact of uncertainty in permeability on transmissivity and associated performance.

\section{Stacking of aquifers}

If the vertical distance between individual aquifers is limited it can be considered to jointly perforate multiple aquifers in order to increase the transmissivity. Therefore stacked maps have been generated for a number of aquifers representing a vertical accumulation of aquifers. Stacked maps could identify possible prospective areas that, in contrast to single aquifer perforation, could now produce sufficient flow rates.

The transmissivity $(\mathrm{kH})$ distribution for each aquifer has been generated by Monte Carlo sampling. In the sampling, the summation of the thickness $\left(\mathrm{H}_{\text {sum }}\right)$ and transmissivity $\left(\mathrm{kH}_{\text {sum }}\right)$ is used to obtain the stacked permeability for that sample through:

$$
\ln \left(\mathrm{k}_{\text {stacked }}\right)=\ln \left(\mathrm{kH}_{\text {sum }} / \mathrm{H}_{\text {sum }}\right)
$$

From the generated sample distribution the average and standard deviation of $\ln \left(\mathrm{k}_{\text {stacked }}\right)$ is determined. These figures represent the average and standard deviation of the lognormal permeability distribution of the stacked aquifer. The standard deviation of the summed thickness $\left(\mathrm{H}_{\text {sum }}\right)$ is set to a negligibly low, fixed number. Consequently, the uncertainty of the stacked aquifer transmissivity has been fully included in the uncertainty of permeability. To ensure a representative calculation of the average water temperature of the aquifer stack, the individual aquifer temperatures are averaged weighted for their average transmissivity. Stacked porosity maps have not been generated.

\section{Results}

The characterisation of the 20 selected aquifers and the additional four stacked aquifer sequences (Table 1 ) resulted in a set of 6 property maps accompanied by uncertainty maps (Table 4) per aquifer. The transmissivity maps have been used as input to an assessment of geothermal resource potential, presented in Van Wees et al. (this issue), and Kramers et al. (this issue). All maps have been incorporated in ThermoGIS (www.thermogis.nl).

The mapped key performance indicators reservoir depth (as proxy for temperature) and transmissivity allow the first order identification of prospective areas. Regions with a minimum transmissivity of $10 \mathrm{Dm}$ (cf. Kramers et al., this issue), combined with a minimum depth of $1200 \mathrm{~m}$ and $1800 \mathrm{~m}$ may be suitable areas for geothermal greenhouse and spatial heating respectively. Figure 14 gives an overview of the transmissivity of the 4 stacked aquifer sequences, combined with a depth contour of $1200 \mathrm{~m}$ or $1800 \mathrm{~m}$.

The Rotliegend aquifers (R0-stacked) have the best transmissivity in the northern and northwestern part of the Netherlands. The depth polygon indicates some temperature restrictions for spatial heating in the area around the IJsselmeer. The prospective areas of the Triassic aquifers (TR-stacked) are located in the West Netherlands Basin and Roer Valley Graben as well as in the province of Drenthe. In the central part of the Roer Valley Graben the transmissivity is below $10 \mathrm{Dm}$, probably due to deep burial of the Triassic aquifers. The stacked sequence of Lower Cretaceous and Upper Jurassic aquifers (JK-stacked) is most prospective in the southwestern part of the West Netherlands Basin. The patches in the northern part of the Netherlands show either low transmissivity or are constrained by the aquifer temperature. The aquifers of the North Sea Supergroup (N-stacked) are characterised by overall good quality, but the limiting parameter is temperature.

Despite the large amount of data used to estimate transmissivity, the uncertainty remains high. An example for the effect of the uncertainty is given in Fig. 13, where the P30, P50 and P70 maps for the transmissivity of the Rotliegend aquifers are shown. A higher probability (P70) results is a decimation of the prospective area, whereas a lower probability (P30) doubles the prospective area.

\section{Discussion}

The modelling approach described in this paper is strongly data driven. The results and related uncertainties are therefore directly related to the quality of the input data and the data density. The result can be improved by adding data or by incorporating assumptions based on geological expertise and experience. Improvement can be achieved in two independent ways. First, the used porosity-permeability relationships can be

Table 4. Maps generated in geothermal characterisation. SD refers to standard deviation, P10-P90 refers to a probability of 10-90\%.

\begin{tabular}{llll}
\hline ThermoGIS map & Units & Uncertainty & Description \\
\hline Depth & $\mathrm{m}$ & - & Top depth map for each aquifer separately \\
Thickness & $\mathrm{m}$ & $\mathrm{SD}$ & Thickness map of each aquifer and stacked in depositions overlay each other directly \\
Porosity & $\%$ & $\mathrm{SD}$ & Porosity based on digitally available well log data for each aquifer separately \\
Permeability & $\mathrm{mD}$ & $\mathrm{SD}$ & Permeability mapped based on porosity mapping results for each aquifer separately \\
Transmissivity & $\mathrm{mDm}$ & $\mathrm{P} 10, \mathrm{P} 30, \mathrm{P} 50$, P70, P90 & Maps generated by multiplying thickness and permeability maps for each aquifer separately \\
Temperature & ${ }^{\circ} \mathrm{C}$ & - & Maps generated from a 3D model of the temperature based on well data \\
\hline
\end{tabular}



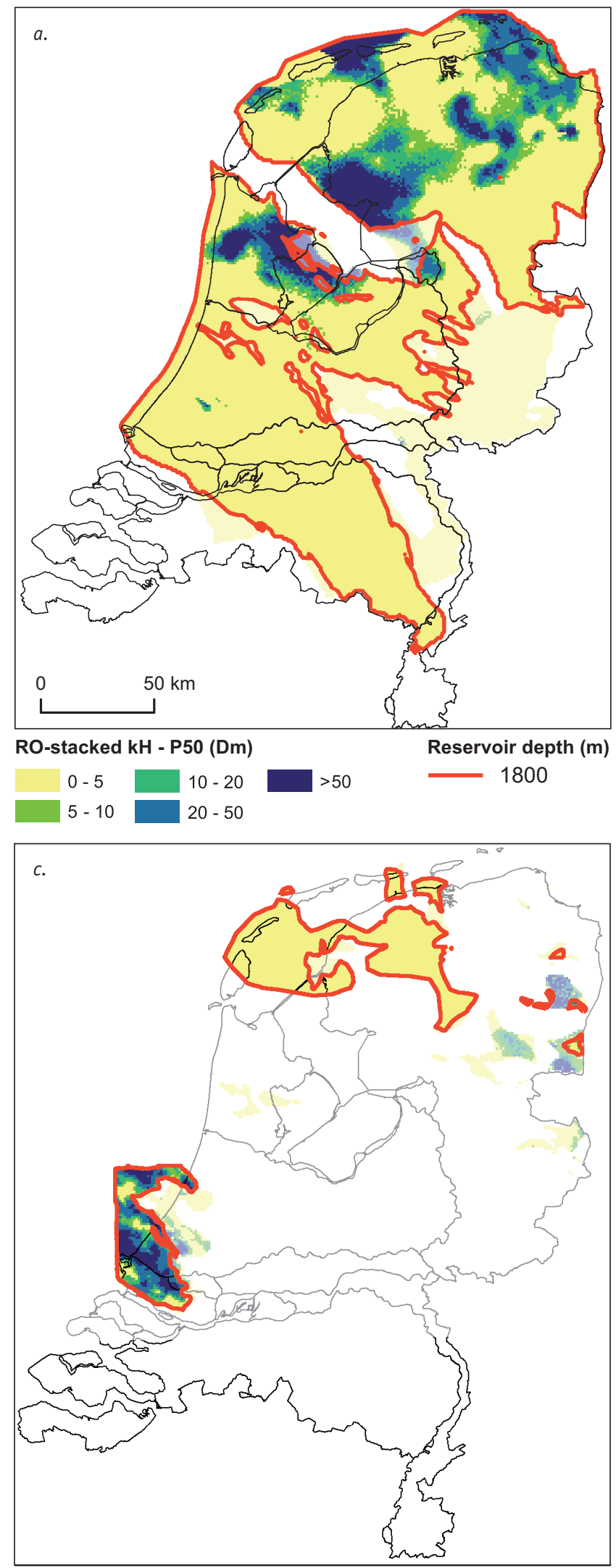

JK-stacked P50 (Dm)

0-5 $10-20$

Reservoir depth (m)

$5-10$

$20-50$

Fig. 14. Transmissivity of the stacked sequences of: $a$. Rotliegend; $b$. Triassic; $c$. Lower Cretaceous and Upper Jurassic; and d. North Sea Supergroup aquifers. Areas with reservoir depth between 1800 and $1200 \mathrm{~m}$ are transparent.
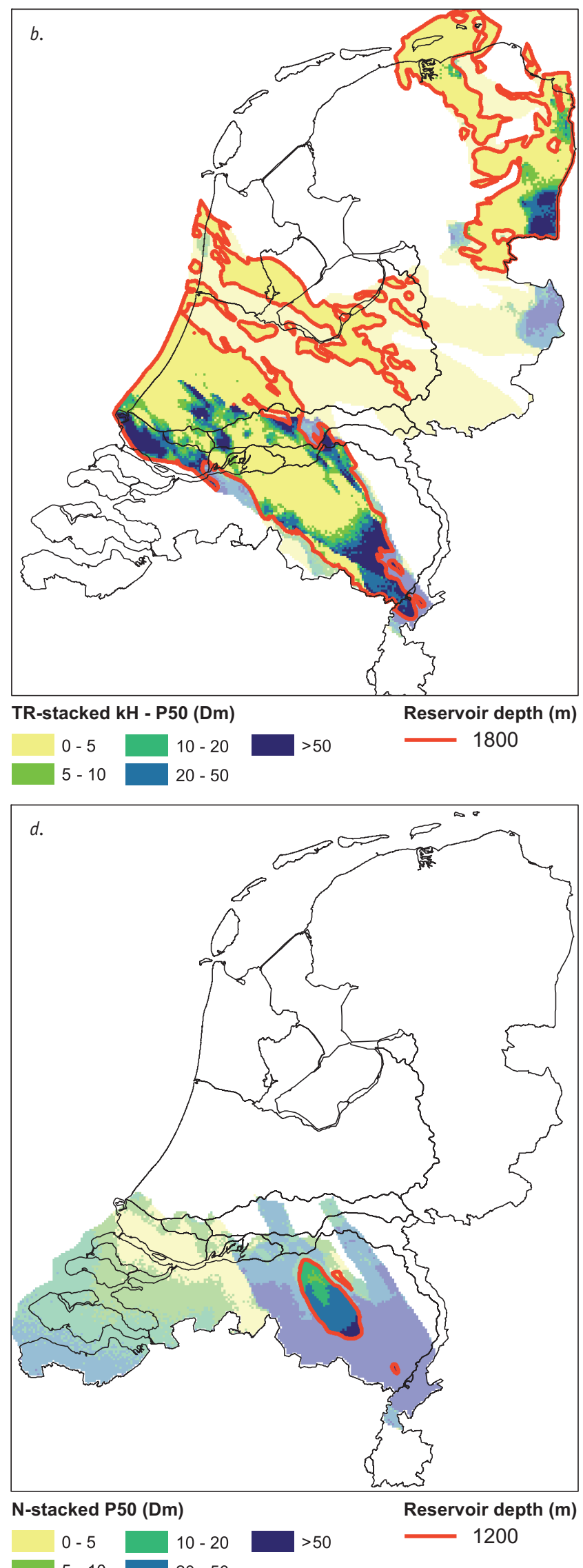
reviewed and revised in the light of data clustering and filtering in order to derive a more robust poro-perm relation. In case of limited data available, this should be achieved by incorporating expert knowledge. Secondly, the spatial data distribution is currently based on correlation of data points expressed in a variogram. Incorporation of sedimentary facies distributions in the modelling workflow, along with diagenesis and cementation, could also improve the model. A third improvement can be achieved by adding extra data. Besides data derived from welllogs and core measurements, incorporation of well test results should have large impact on the estimation of transmissivity.

This modelling approach is developed for regional characterisation of reservoirs and therefore tends to oversee local heterogeneities, in particular permeability. Prospective areas can be identified on the resulting transmissivity maps, but should be examined more thoroughly in a geothermal exploration phase.

\section{Conclusion}

The presented workflow shows that regional transmissivity maps and underlying uncertainty can be built for geothermal aquifers, taking oil and gas well data and mapping results from detailed seismic interpretation into account. We have shown that burial anomalies can have a significant effect on regional assessment of porosity and permeability of geothermal aquifers. In general, the prospectivity of basin flanks (with few data) of inverted basins (with most well data control) can be significantly enhanced by incorporating burial anomalies.

Mapping of the key parameters transmissivity and temperature shows favorable aquifer conditions in the northern part of the Netherlands for the Rotliegend aquifers, while in the western and southern parts of the Netherlands Triassic and Upper Cretaceous / Jurassic aquifers show prospectivity. Despite the high transmissivity of the aquifers of the North Sea Supergroup, the limited depth and therefore temperature reduces the prospective geothermal area significantly.

The results show a considerable remaining uncertainty of transmissivity values, due to the lack of data and the heterogeneous spatial data distribution. For underexplored areas this bears a significant risk, but this can also result in much higher flowrates than originally expected, representing and upside in project performance. In part these uncertainties may be significantly reduced by adding well test results and facies parameters for the map interpolation in future work.

\section{Acknowledgements}

We thank H. Kombrink, the editor, and the reviewers R. Herber and R. Gaup for their constructive reviews that significantly improved the quality of this paper.

\section{References}

Allen, P.A. \& Allen, J.R., 2005. Basin Analysis: Principles and Applications. Blackwell Publishing (0xford), 549 pp.

Athy, L.F., 1930. Density, porosity and compaction of sedimentary rocks. American Association of Petroleum Geophysicists Bulletin 14: 1-24.

Bond, G.C. \& Kominz, M.A., 1984. Construction of tectonic subsidence curves for the early Paleozoic miogeocline, southern Canadian Rocky Mountains: implications for subsidence mechanisms, age of breakup, and crustal thinning. Bulletin of the Geological Society of America 95: 155-173.

Bonté, D., Van Wees, J.-D. \& Verweij, J.M., 2012. Subsurface temperature of the onshore Netherlands: new temperature dataset and modelling. Netherlands Journal of Geosciences 91-4: 491-515, this issue.

De Jager, J., 2007. Geological development. In: Wong, T.E., Batjes, D.A.J. \& De Jager, J. (eds): Geology of the Netherlands. Royal Netherlands Academy of Arts and Sciences (KNAW) (Amsterdam): 5-26.

Duin, E.J.T., Doornenbal, J.C., Rijkers, R.H.B., Verbeek, J.W. \& Wong, T.E., 2006. Subsurface structure of the Netherlands; results of recent onshore and offshore mapping. Netherlands Journal of Geosciences 85: 245-276.

Hantschel, T. \& Kauerauf, A.I., 2009. Fundamentals of Basin and Petroleum Systems Modeling. Springer-Verlag (Berlin Heidelberg), 476 pp.

International Energy Agency (IEA), 2011. Technology Roadmap Geothermal Heat and Power. www.iea.org.

Kombrink, H., Doornenbal, J.C., Duin, E.J.T., Den Dulk, M., Van Gessel, S.F., Ten Veen, J.H. \& Witmans, N., 2012. New insights into the geological structure of the Netherlands; results of a detailed mapping project. Netherlands Journal of Geosciences 91-4: 419-446, this issue.

Kramers, L., Van Wees, J.-D., Pluymaekers, M.P.D., Kronimus, A. \& Boxem, T., 2012. Direct heat resource assessment and subsurface information systems for geothermal aquifers; the Dutch perspective. Netherlands Journal of Geosciences 91-4: 637-649, this issue.

Lokhorst, A. \& Wong, T.E., 2007. Geothermal Energy. In: Wong, T.E., Batjes, D.A.J. \& De Jager, J. (eds): Geology of the Netherlands. Royal Netherlands Academy of Arts and Sciences (KNAW) (Amsterdam): 341-346.

Luijendijk, E., Van Balen, R., Ter Voorde, M. \& Andriessen, P., 2011. Reconstructing the Late Cretaceous inversion of the Roer Valley Graben (southern Netherlands) using a new model that integrates burial and provenance history with ssion track thermochronology. Journal of Geophysical Research 116: 1-19.

Nelskamp, S. \& Verweij, J.M., 2012. Using basin modeling for geothermal energy exploration in the Netherlands - an example from the West Netherlands Basin and Roer Valley Graben. TN0 (Utrecht). Report number TN0-060-UT-2012-00245, $113 \mathrm{pp}$.

Pape, H., Clauser, C. \& Iffland, J., 1999. Permeability prediction for reservoir sandstones based on fractal pore space geometry. Geophysics 64: 1447-1460.

Schlumberger, 1991. Log Interpretation Principles/Applications. Schlumberger (Texas).

TNO-NITG, 2004. Geological Atlas of the Subsurface of the Netherlands - onshore. Netherlands Institute of Applied Geoscience TN0 (Utrecht), 104 pp.

Ungemach, P., Antics, M. \& Papachristou, M., 2005. Sustainable Reservoir Management. World Geothermal Congress (Antalya, Turkey). 
Van Adrichem Boogaert, H.A. \& Kouwe, W.F.P., 1993. Stratigraphic nomenclature of the Netherlands, revision and update by RGD and NOGEPA, Section A, General. Mededelingen Rijks Geologische Dienst 50: 1-40.

Van Balen, R.T., Bergen, G.v., Leeuw, C.d., Pagnier, H.J.M., Simmelink, H., Van Wees, J.-D. \& Verweij, J.M., 2000. Modeling the hydrocarbon generation and migration in the West Netherlands Basin, the Netherlands. Netherlands Journal of Geosciences 79: 29-44.

Van Dalfsen, W., Mijnlieff, H. \& Simmelink, E., 2005. Interval velocities of a Triassic claystone: Key to burial history and velocity modelling. EAGE 2005, Poster presentation.

Van Doorn, T.H.M. \& Rijkers, R.H.B., 2002. The Netherlands. In: Hurter, S. \& Haenel, R. (eds): Atlas of Geothermal Resources in the European Community. Office for Official Publications of the European Communities (Luxemburg). Publication EUR 17811.

Van Wees, J.-D., Boxem, T., Bonté, D., Pluymaekers, M., Nelskamp, S. \& Kramers, L., 2011. Regional assessment of aquifer permeability: the importance of burial anomalies. EAGE-SES 2011, Conference Abstracts.

Van Wees, J.-D., Kronimus, A., Van Putten, M., Pluymaekers, M.P.D., Mijnlieff, H.F., Van Hooff, P., Obdam, A. \& Kramers, L., 2012. Geothermal aquifer performance assessment for direct heat production - Methodology and application to Rotliegend aquifers. Netherlands Journal of Geosciences 91-4: 651-665, this issue.

Van Wees, J.-D., Van Bergen, F., David, P., Nepveu, M., Beekman, F., Cloetingh, S.A.P.L. \& Bonté, D., 2009. Probabilistic tectonic heat flow modeling for basin maturation: Assessment method and applications. Marine and Petroleum Geology 26: 536-551.

Vis, G.-J., Van Gessel, S., Mijnlieff, H., Pluymaekers, M., Hettelaar, J. \& Stegers, D., 2010. Lower Cretaceous Rijnland Group aquifers in the West Netherlands Basin: suitability for geothermal energy. TNO (Utrecht). Report number TN0-034-UT-2009-02410, 55 pp.

Wiers, J., 2001. A hydrogeological characterization and 3D groundwaterflow model of the Roer Valley Graben. Master thesis, VU (Amsterdam).

Worum, G., 2004. Modelling of fault reactivation potential and quantification of inversion tectonics in the southern Netherlands. PhD thesis, Vrije Universiteit (Amsterdam), $152 \mathrm{pp}$.

Xu, W., Tran, T.T., Srivastava, R.M. \& Journel, A.G., 1992. Integrating seismic data in reservoir modeling: The collocated cokriging alternative. SPE 24742. 